\title{
RESEARCH
}

Open Access

\section{Efficacy of upfront hepatectomy without neoadjuvant chemotherapy for resectable colorectal liver metastasis}

Kosuke Ono ${ }^{1}$, Tomoyuki Abe ${ }^{1 *} \mathbb{D}$, Akihiko Oshita ${ }^{1,2}$, Yusuke Sumi ${ }^{1}$, Takuya Yano ${ }^{3}$, Hiroshi Okuda', Manabu Kurayoshi ${ }^{1}$, Tsuyoshi Kobayashi ${ }^{2}$, Hideki Ohdan², Toshio Noriyuki ${ }^{1,2}$ and Masahiro Nakahara ${ }^{1}$

\begin{abstract}
Background: Hepatectomy for resectable colorectal liver metastasis (CRLM) is recommended. However, the efficacy of upfront hepatectomy without neoadjuvant chemotherapy (NAC) is unclear due to the uncertainty of perioperative systemic chemotherapy. Moreover, it is crucial to predict the prognosis when considering perioperative chemotherapy. This study evaluated the impact of neoadjuvant chemotherapy on the prognosis of patients with resectable CRLM and assessed the usefulness of Beppu's nomogram for predicting prognosis.

Methods: This retrospective study identified 88 consecutive inpatients who underwent primary hepatic resection for CRLM; 58 received neoadjuvant chemotherapy and 30 underwent upfront surgery. Factors associated with recurrence-free survival were identified via univariate and multivariate analysis. Furthermore, propensity score analysis using inverse probability of treatment weighting (IPTW) was performed.

Results: On univariate analysis, poor recurrence-free survival was associated with multiple tumors, advanced primary tumor stage, vascular invasion by the primary tumor, a Beppu's nomogram score $\geq 6$, and neoadjuvant chemotherapy. On multivariate analysis, a Beppu's nomogram score $\geq 6$ and neoadjuvant chemotherapy were independent risk factors for recurrence. Neoadjuvant chemotherapy recipients had a higher incidence of lymph node metastasis and vascular invasion than non-recipients. Propensity score analysis revealed no significant difference in the recurrence-free survival rate between these groups.
\end{abstract}

Conclusions: Our results show that upfront hepatectomy without neoadjuvant chemotherapy can be considered for resectable CRLM treatment. Beppu's nomogram score can be a tool for predicting the prognosis of patients with CRLM.

Keywords: Beppu's nomogram score, Neoadjuvant chemotherapy, Hepatectomy

* Correspondence: tabehiroshima@gmail.com

'Department of Surgery, Onomichi General Hospital, 1-10-23 Hirahara Onomichi, Hiroshima 722-8508, Japan

Full list of author information is available at the end of the article

(c) The Author(s). 2021 Open Access This article is licensed under a Creative Commons Attribution 4.0 International License, which permits use, sharing, adaptation, distribution and reproduction in any medium or format, as long as you give appropriate credit to the original author(s) and the source, provide a link to the Creative Commons licence, and indicate if changes were made. The images or other third party material in this article are included in the article's Creative Commons licence, unless indicated otherwise in a credit line to the material. If material is not included in the article's Creative Commons licence and your intended use is not permitted by statutory regulation or exceeds the permitted use, you will need to obtain permission directly from the copyright holder. To view a copy of this licence, visit http://creativecommons.org/licenses/by/4.0/. The Creative Commons Public Domain Dedication waiver (http://creativecommons.org/publicdomain/zero/1.0/) applies to the data made available in this article, unless otherwise stated in a credit line to the data. 


\section{Background}

Colorectal cancer (CRC) is the third most common cancer, and its incidence is increasing worldwide [1]. Hepatectomy is the gold standard treatment for colorectal liver metastasis (CRLM). Owing to recent advancements in perioperative surgical management, unresectable CRLMs can now be safely resected by staged hepatectomy [2]. However, even if curative resection is performed, the postoperative recurrence rate in the remnant liver is high (approximately 75\%) [3] and the 5year survival rate is dismal (33-61\%) [4].

Perioperative chemotherapy is a potential strategy for improving the long-term survival of patients with CRLM. There is evidence supporting the efficacy of postoperative adjuvant chemotherapy [5]. However, the efficacy of neoadjuvant chemotherapy (NAC) for resectable CRLM remains controversial. In the EORTC 40983 clinical trial, patients with resectable CRLM who received perioperative NAC had a better 3-year progression-free survival rate than those who received surgery alone [6]. Following this trial, the European Society for Medical Oncology recommended perioperative adjuvant chemotherapy for CRLM [7]. However, a subsequent study of the patient groups in the EORTC 49083 found no significant effect of NAC on the 3 - or 5-year overall survival (OS) rate [8]. In addition, a review of chemotherapy treatments for resectable CRLM found no difference in the OS rate between patients who received and those who did not receive preoperative chemotherapy [9]. Thus, the efficacy of upfront hepatectomy without neoadjuvant chemotherapy (NAC) is unclear.

Accurate prediction of prognosis is crucial when considering perioperative chemotherapy strategies. In this study, we used Beppu's nomogram as a prognostic tool. This nomogram consists of six preoperative factors, is simple to apply, and has been known to predict diseasefree survival (DFS) rates in CRLM patients after radical resection [10]. Although this nomogram is simple and convenient for clinical use, it is unclear whether it is useful in combination with recent advances in chemotherapy because it is a nomogram analyzed based on cases from 2000 to 2004. Higuchi et al. validated this nomogram and demonstrated its efficacy [11]. However, this was confirmed in patients from 2006 to 2011. Therefore, the usefulness of Beppu's score even in these days when treatments for CRLM such as chemotherapy regimens are evolving remains uncertain.

This study examined the efficacy of NAC for CRLM with radical resection and the usefulness of Beppu's nomogram in predicting prognosis.

\section{Methods}

\section{Patients}

We conducted a retrospective cohort study of patients who underwent primary hepatic resection for CRLM in the Department of Surgery at Onomichi General Hospital between June 2006 and April 2019. It was conducted in accordance with the ethical standards of the 1964 Declaration of Helsinki. The study design was approved by our institutional review board (OJH-201509), and all patients provided informed consent for their treatment.

\section{Surgery}

The initial surgery was performed using a laparoscopic or open method. The extent of resection was determined by the location of the tumor. Partial resection was selected if possible; if not, segment resection or lobectomy was selected to preserve liver function. The Pringle method was used as much as possible to control bleeding. One surgical hepatobiliary team performed the surgery in this study.

\section{NAC}

The standard treatment at our facility has been NAC. The administration period depends on the case and regimen; however, the treatment usually includes six courses. The regimens were as follows: 5-fluorouracil (5FU), leucovorin (LV), and oxaliplatin (FOLFOX) or capecitabine and oxaliplatin (CAPOX); 5FU, LV, and irinotecan (FOLFIRI); and tegafur/gimeracil/oteracil (TS-1) or tegafur/uracil with either LV (UFT/UZEL) or capecitabine. In addition, the FOLFOX and FOLFIRI regimens included a molecularly targeted agent (bevacizumab, cetuximab, or panitumumab) if needed. Upfront hepatectomy was performed in patients who refused to undergo NAC and in those whose general condition contraindicated NAC.

\section{Morbidity}

Survival values were calculated from the date of surgery.

\section{Follow-up strategy}

All patients were followed until death and underwent annual follow-ups consisting of abdominal ultrasonography and laboratory tests for tumor markers, namely, carbohydrate antigen 19-9 (CA19-9) and carcinoembryonic antigen. Dynamic computed tomography (CT) was conducted every 6 months. If a definitive diagnosis of recurrence could not be established based on tumor marker data, ultrasonography-guided biopsy imaging (CT, magnetic resonance imaging, endoscopic ultrasonography, or fluorodeoxyglucose-positron emission tomography) was performed.

\section{Beppu's nomogram score}

The following six preoperative factors were used to create the nomogram for DFS: synchronous metastasis (3 points); positive primary lymph node (3 points); tumor 
number, ( 4 points for $2-4$ tumors and 9 points for $\geq 5$ tumors); largest tumor diameter $>5 \mathrm{~cm}$ ( 2 points); extrahepatic metastasis at hepatectomy (4 points); and preoperative CA19-9 level > 100 (4 points). Zero, 5, 10, and $>10$ points corresponded to estimated median DFS times of $>8.4$ years, 1.9 years, 1 year, and $<0.6$ years, respectively. The total preoperative Beppu's nomogram scores ranged from 0 to 25 points.

\section{Liver metastasis classification and prognostic grade classification}

The Japanese Classification of Colorectal Carcinoma Hclassifications is based on the number and maximum size of tumors (General Rules for Clinical and Pathologic Studies on Cancer of the Colon, Rectum and Anus, 7th Japanese edition, 2009; H0, no liver metastasis; H1, number of metastasis $<4$ and size of the largest tumor $<5 \mathrm{~cm}$; $\mathrm{H} 2$, other than $\mathrm{H} 1$ or $\mathrm{H} 3$; $\mathrm{H} 3$, number of metastasis $>5$ and size of largest tumor $>5 \mathrm{~cm}$ ). Prognosis classification combines the $\mathrm{H}$-classification with the degree of lymph node metastasis of the primary lesion and the presence or absence of distance metastasis: grade A, $\mathrm{H} 1$ and N0 or N1 and $\mathrm{M} 0$; grade $\mathrm{B}, \mathrm{H} 1$ and $\mathrm{N} 2$ and $\mathrm{M} 0$ and $\mathrm{H} 2$ and $\mathrm{N} 0$ or $\mathrm{N} 1$ and $\mathrm{M} 0$; and grade $\mathrm{C}, \mathrm{H} 1$ and $\mathrm{N} 3$ and $\mathrm{M} 0, \mathrm{H} 2$ and $\mathrm{N} 2$ or N3 and M0, or all M1 cases and all H3 cases.

\section{Statistical analyses}

Recurrence-free survival (RFS) rates were determined using the Kaplan-Meier method and the log-rank test. Multivariate analyses for RFS were performed using Cox's regression model. Appropriate calibration of the model was indicated by a $P$-value of 0.620 in the HosmerLemeshow test, and good discrimination was indicated by a C-statistic of 0.773 with a $95 \%$ confidence interval (CI) of 0.662-0.884 and a $P$-value $<0.001$. Propensity score analysis using inverse probability of treatment weighting (IPTW) was performed to overcome bias related to the different distributions of the covariates between NAC recipients and non-recipients. In the weighted variables such as CEA, lymph node metastasis, lymphatic invasion, and Beppu's score, we used a Cox regression model to regress recurrence-free survival between patients with NAC and patients with upfront surgery and used a robust variance estimator [12]. After IPTW processing, differences in RFS between these groups were tested using Cox regression and multiple logistic regression analyses. Two-tailed $P$ values $<0.05$ were considered statistically significant, and all analyses were performed using SPSS software (version 24; IBM, Armonk, NY, USA).

\section{Results}

Patients

In total, 88 patients underwent initial hepatectomy for CRLM at our center.
The patients' clinicopathological characteristics are outlined in Table 1 . Of the 88 patients, 63 (72\%) were men and $25(28 \%)$ were women, and the median age was 70 years (Table 1). The primary tumor was located in the colon in 47 (53\%) patients and the rectum in 41 (47\%) patients; it was left-sided in 67 (76\%) patients and right-sided in 12 (14\%) patients. Synchronous liver metastasis, metachronous CRLM, and synchronous lung metastasis were detected in 42 (48\%), 46 (52\%), and 5 (6\%) patients, respectively. Moreover, 18 patients (39\%) with metachronous liver metastasis received chemotherapy along with colorectal resection for liver metastasis. Forty-six (52\%) patients had 1 liver metastasis, 28 (32\%) had 2-4 liver metastases, and 14 (16\%) had $\geq 5$ liver metastases. The median tumor number was 1 (range, 115), and the median tumor size was $17 \mathrm{~mm}$. Forty-two (48\%) patients were with TNM classification stage I-III and 46 (52\%) with stage IV.

Histologically, 46 (52\%) primary tumors were welldifferentiated adenocarcinomas; the remaining were of various types. Lymphatic invasion was negative in 29 (33\%) and positive in 59 (67\%) patients. Venous invasion was negative in 59 (67\%) and positive in 29 (33\%) patients. Regional lymph node metastasis around the primary tumor was negative in 27 (31\%) patients. Beppu's nomogram score was $>6$ points in $54(61 \%)$ and $>10$ in 31 (39\%) patients. NAC was administered in 58 (67\%) patients: 5-fluorouracil (5FU), leucovorin (LV), and oxaliplatin (FOLFOX) or capecitabine and oxaliplatin (CAPOX) $(n=34)$; 5FU, LV, and irinotecan (FOLFIRI, $n$ $=10)$; and tegafur/gimeracil/oteracil (TS-1) or tegafur/ uracil with either LV (UFT/UZEL) or capecitabine ( $n=$ 14). The median interval period between NAC and hepatectomy was 48 (19-131) days. Major hepatectomy (resection of three or more Couinaud segments) was performed in 20 (23\%) patients. Laparoscopic hepatectomy was performed in 26 (29.5\%) patients. The KaplanMeier of OS and RFS was presented in Figure 1. OS was not different in both group $(P=0.879)$; however, RFS was significantly shorter in the NAC+ group than in the NAC- group $(P=0.029)$.

\section{Univariate and multivariate analyses for factors associated with the 3-year RFS rate of patients with resectable CRLM}

On univariate analysis, the following five factors were significantly associated with a low RFS rate: tumor number $\geq 5(P=0.03)$, TNM stage IV at the time of surgery $(P=0.041)$, liver metastasis classification $\mathrm{H} 2-3(P=$ $0.013)$, prognosis grade classification $\mathrm{B}-\mathrm{C}(P=0.005)$, vascular invasion $(P=0.021)$, Beppu's nomogram score $\geq 6(P=0.027)$, and NAC $(P=0.029)$ (Table 1$)$. On multivariate analysis, a Beppu's nomogram score $\geq 6$ (hazard ratio, 1.994, $P=0.027$ ) and NAC (hazard ratio, 
Table 1 Results of univariate and multivariate analyses of the clinicopathological factors for recurrence-free survival rates

\begin{tabular}{|c|c|c|c|}
\hline \multirow[t]{2}{*}{ Factors } & \multicolumn{2}{|c|}{ Univariate analysis } & \multirow{2}{*}{$\begin{array}{l}\text { Multivariate analysis } \\
P \text {-value }\end{array}$} \\
\hline & $\bar{N}$ & 3 years $(\%)$ & \\
\hline \multicolumn{4}{|l|}{ Gender } \\
\hline Male & 63 & 32.6 & - \\
\hline Female & 25 & 40.9 & 0.361 \\
\hline \multicolumn{4}{|l|}{ BMl } \\
\hline$<23$ & 39 & 35.9 & - \\
\hline$\geq 23$ & 49 & 34.4 & 0.910 \\
\hline \multicolumn{4}{|l|}{ Location } \\
\hline Colon & 47 & 34.8 & - \\
\hline Rectum & 41 & 34.6 & 0.853 \\
\hline \multicolumn{4}{|l|}{ Location } \\
\hline Right side & 12 & 15.0 & \\
\hline Left side & 67 & 37.2 & \\
\hline Transverse & 9 & 44.4 & 0.125 \\
\hline \multicolumn{4}{|c|}{ Timing of liver metastasis } \\
\hline Metachronous & 46 & 39.4 & \\
\hline Synchronous & 42 & 30.7 & 0.190 \\
\hline \multicolumn{4}{|c|}{ Synchronous lung metastasis } \\
\hline Absent & 83 & 35.0 & \\
\hline Present & 5 & 40.0 & 0.590 \\
\hline \multicolumn{4}{|l|}{ Number of tumors } \\
\hline 1 & 46 & 49.0 & \\
\hline $2-4$ & 28 & 20.8 & \\
\hline$\geq 5$ & 14 & 19.2 & 0.030 \\
\hline \multicolumn{4}{|c|}{ Largest tumor diameter } \\
\hline$<5 \mathrm{~cm}$ & 73 & 34.1 & \\
\hline$\geq 5 \mathrm{~cm}$ & 15 & 37.0 & 0.999 \\
\hline \multicolumn{4}{|c|}{ CEA level (before hepatectomy) } \\
\hline$<5 \mathrm{ng} / \mathrm{ml}$ & 35 & 27.9 & \\
\hline$\geq 5 \mathrm{ng} / \mathrm{mL}$ & 52 & 38.5 & 0.438 \\
\hline \multicolumn{4}{|c|}{ CA19-9 level (before hepatectomy) } \\
\hline$<38 \mathrm{U} / \mathrm{mL}$ & 63 & 29.6 & \\
\hline$\geq 38 \mathrm{U} / \mathrm{mL}$ & 24 & 49.7 & 0.759 \\
\hline \multicolumn{4}{|l|}{ Stage (primary tumor) } \\
\hline$|-|||$ & 42 & 43.7 & \\
\hline IV & 46 & 27.3 & 0.041 \\
\hline \multicolumn{4}{|c|}{ Liver metastasis classification } \\
\hline $\mathrm{H} 1$ & 55 & 47.6 & \\
\hline $\mathrm{H} 2-3$ & 28 & 19.9 & 0.013 \\
\hline \multicolumn{4}{|c|}{ Prognosis grade classification } \\
\hline Grade A & 50 & 48.7 & \\
\hline Grade $B, C$ & 32 & 17.3 & 0.005 \\
\hline \multicolumn{4}{|c|}{ Primary tumor differentiation } \\
\hline Well-differentiated & 46 & 35.5 & \\
\hline
\end{tabular}


Table 1 Results of univariate and multivariate analyses of the clinicopathological factors for recurrence-free survival rates (Continued)

\begin{tabular}{|c|c|c|c|}
\hline \multirow[t]{2}{*}{ Factors } & \multicolumn{2}{|c|}{ Univariate analysis } & \multirow{2}{*}{$\begin{array}{l}\text { Multivariate analysis } \\
P \text {-value }\end{array}$} \\
\hline & $\bar{N}$ & 3 years $(\%)$ & \\
\hline Others & 42 & 34.5 & 0.775 \\
\hline \multicolumn{4}{|l|}{ lympatic invasion (primary tumor) } \\
\hline Negative & 29 & 41.5 & \\
\hline Positive & 59 & 31.6 & 0.161 \\
\hline \multicolumn{4}{|c|}{ venous invasion (primary tumor) } \\
\hline Negative & 59 & 43.1 & \\
\hline Positive & 29 & 19.9 & 0.021 \\
\hline \multicolumn{4}{|l|}{ N } \\
\hline Negative & 27 & 42.3 & \\
\hline Positive & 61 & 31.3 & 0.057 \\
\hline \multicolumn{4}{|l|}{ Beppu's nomogram score } \\
\hline$<6$ & 34 & 49.2 & \\
\hline$\geq 6$ & 54 & 26.5 & $0.0271 .994(1.083-3.672) 0.027$ \\
\hline \multicolumn{4}{|c|}{ Chemotherapy before hepatectomy } \\
\hline Absent & 30 & 46.8 & \\
\hline Present & 58 & 29.4 & $0.0291 .962(1.092-3.524) 0.024$ \\
\hline \multicolumn{4}{|l|}{ Operative procedure } \\
\hline Laparoscopic hepatectomy & 26 & 36.1 & \\
\hline Open hepatectomy & 62 & 34.3 & 0.493 \\
\hline
\end{tabular}

$B M I$ body mass index, $m G P S$ modified Glasgow prognostic score, NLR neutorophil lymphocyte ratio, PNI prognostic nutrition index, CEA carcinoembryonic antigen, CA19-9 carbohydrate antigen 19-9

1.962, $P=0.024)$ were independent risk factors for RFS (Table 1).

\section{Clinicopathological characteristics of the NAC+ and NAC- groups}

Table 2 compares the characteristics of the patients who received NAC (NAC+ group) and those who did not (NAC- group). There were no significant differences in the general conditions of the groups at the time of hepatectomy. However, values related to the primary tumor, including the incidence of lymph node metastasis $(P=0.012)$ and vascular invasion $(P$ $=0.009)$, were higher in the NAC+ group than in the $\mathrm{NAC}$ - group.

\section{Prognostic impact of NAC after IPTW}

After IPTW, there was no significant difference in the RFS rate between the NAC+ and NAC- groups $(P=$ 0.724) (Table 3, Fig. 2).

\section{Discussion}

This study showed the following for patients with resectable CRLM: NAC does not improve long-term prognosis, even when radical resection is performed; low Beppu's nomogram scores are strongly associated with favorable long-term prognosis; and upfront hepatectomy is an effective treatment strategy. The aims of NAC include preservation of the remnant liver volume by tumor shrinkage and securing the surgical margin. NAC is an early treatment for micro-metastases, and determination of its efficacy is critical. Although evidence of NAC efficacy in various cancers is increasing $[13,14]$, there are no data supporting its use in CRLM.

In this study, lymph node metastasis, lymphatic invasion, and high Beppu's nomogram scores were more likely in patients who received NAC than in those who did not. However, NAC did not improve prognosis, even after the background characteristics of the two groups were aligned via IPTW.

The 2016 revised ESMO guideline recommends upfront hepatectomy for patients with clearly resectable CRLM and favorable prognostic indicators [15]. However, in advanced cases with high hepatic tumor loads and multiple tumors, perioperative systemic chemotherapy is essential for down-staging unresectable CRLM. Moreover, shortening the interval between NAC and hepatectomy improves the outcome in advanced CRLM cases [16]. Along with advances in surgical technology such as two-stage hepatectomy (e.g., liver partition and portal vein ligation for staged hepatectomy), the use of NAC has increased the number of cases in which conversion surgery is possible [17]. 


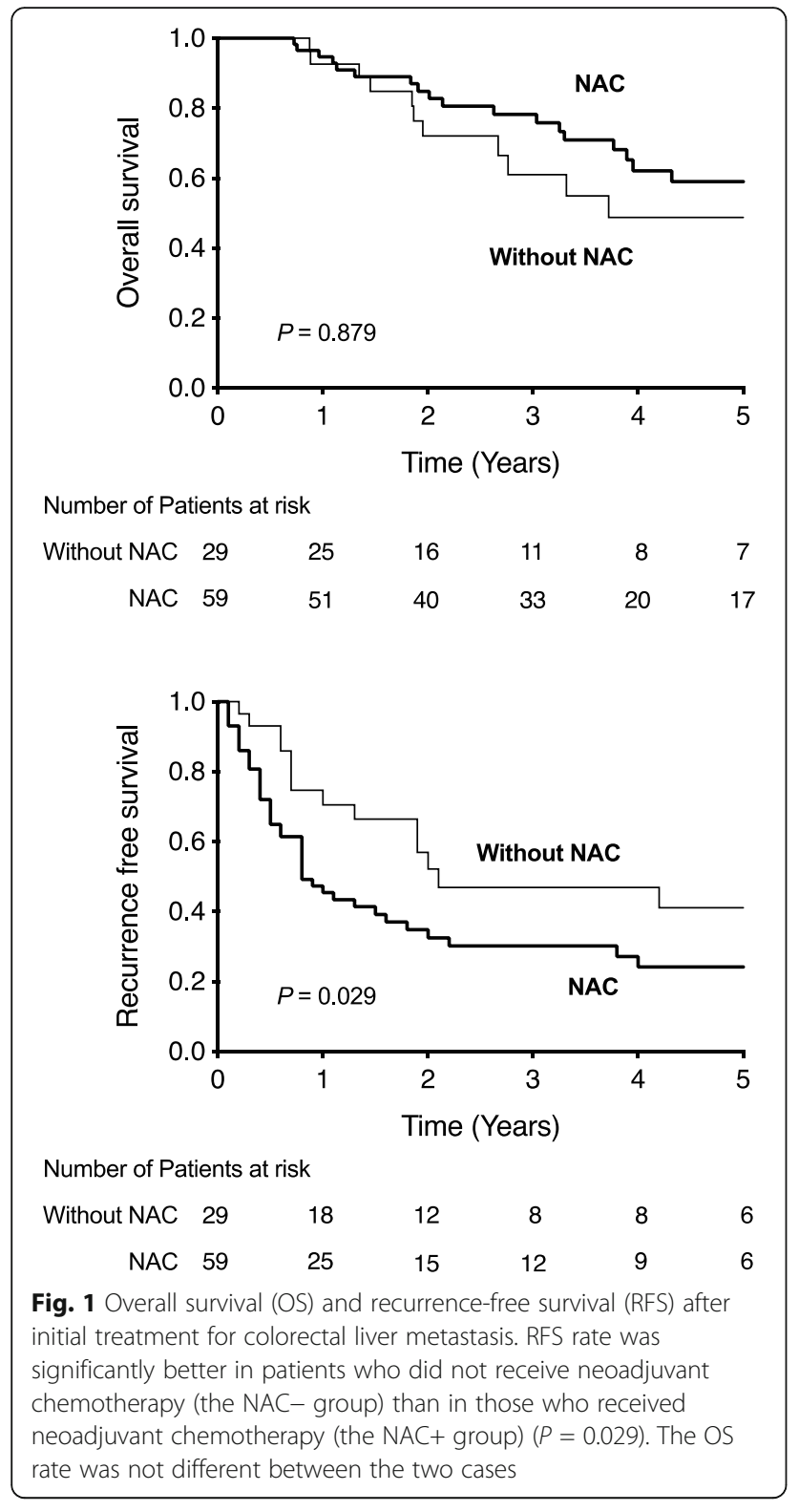

The present study showed significant correlation between Beppu's nomogram score and prognosis. This relatively simple nomogram was easily applied in the patients of our study. The usefulness of the nomogram, which was proposed in 2004, was thought to be unclear as the treatment policy changed as times changed. However, it is interesting that this nomogram was useful even though chemotherapy regimen has changed during the 13-year study period.

This study had a few limitations. First, it was retrospective and based on a single-center experience. Second, the relatively small sample size made it difficult to draw statistical inferences. Finally, the NAC regimens varied considerably. Considering the possibility of selection bias due to this background, propensity score
Table 2 Comparison of patients' characteristics between patients with neoadjuvant chemotherapy and without neoadjuvant chemotherapy

\begin{tabular}{llll}
\hline & $\begin{array}{l}\text { NAC (-) } \\
(\boldsymbol{n}=\mathbf{3 0})\end{array}$ & $\begin{array}{l}\text { NAC (+) } \\
(\boldsymbol{n}=\mathbf{5 8})\end{array}$ & $\begin{array}{l}\boldsymbol{P} \text {-value } \\
\text { Male sex }\end{array}$ \\
$21(72 \%)$ & $42(71 \%)$ & 0.904 \\
Age (years) & $73.5(35-$ & $69(48-85)$ & 0.026 \\
& $86)$ & & \\
BMI (kg/m²) & $22(16-34)$ & $23(15-30)$ & 0.940 \\
Location (colon) & $11(38 \%)$ & $30(51 \%)$ & 0.254 \\
Location (right side) & $3(10 \%)$ & $9(16 \%)$ & 0.585 \\
Timing of liver metastasis & $13(43 \%)$ & $29(50 \%)$ & 0.703 \\
(synchronous) & & & \\
Synchronous lung metastasis & 0 & $5(9 \%)$ & 0.128 \\
Tumor number (multiple) & $14(47 \%)$ & $29(50 \%)$ & 0.938 \\
Tumor number & $1.5(1-7)$ & $1(1-15)$ & 0.521 \\
CEA & $\mathbf{1 3 . 9}$ & $\mathbf{5 . 2 5}$ & $\mathbf{0 . 0 1 1}$ \\
CA19-9 & $\mathbf{( 2 - 1 2 2 4 )}$ & $\mathbf{( 1 . 2 - 1 1 1 . 1 )}$ & \\
& $12.5(2-$ & 10.5 & 0.989
\end{tabular}

Primary tumor differentiation (well)

$\begin{array}{llll}\mathbf{N} \mathbf{1} & \mathbf{1 5}(\mathbf{5 0} \%) & \mathbf{4 6}(\mathbf{7 9 \% )} & \mathbf{0 . 0 1 2} \\ \text { Ly } \mathbf{1} & \mathbf{1 4}(\mathbf{4 7} \%) & \mathbf{4 5}(\mathbf{7 8 \% )} & \mathbf{0 . 0 0 9} \\ \text { Beppu's nomogram score } 6 & \mathbf{1 6}(53 \%) & 38(66 \%) & 0.403 \\ \text { Beppu's nomogram score }>\mathbf{1 0} & \mathbf{5 ( 1 7 \% )} & \mathbf{2 6}(\mathbf{4 5} \%) & \mathbf{0 . 0 1 3} \\ \text { Beppu's nomogram score } & & & 0.092 \\ \text { Clavien-Dindo classification } & 3 & 11 & 0.372 \\ \text { Laparoscopic hepatectomy } & 12(40 \%) & 14(24 \%) & 0.088 \\ \text { Operation time } & 322 & 356 & 0.253 \\ & (86-596) & (127-727) & \\ \text { Intraoperative bleeding } & 205 & 290 & 0.379 \\ & (20-4000) & (20-3020) & \\ \text { PNI } & 46(28-81) & 46(34-61) & 0.605 \\ \text { NLR } & 2.5 & 1.9(0.6-6.2) & 0.154 \\ & (0.3-9.4) & & \\ \text { GPS } & 6 & 13 & 0.949 \\ \text { mGPS } & 3 & 10 & 0.356\end{array}$

Variables in bold are statistically significant $(P<0.05)$. Continuous variables are expressed as median (range). Qualitative variables are expressed as number (\%).BMI body mass index, NAC neoadjuvant chemotherapy, NLR neutrophil-tolymphocyte ratio, PNI prognostic nutritional index, GPS Glasgow prognostic score, $m G P S$ modified Glasgow prognostic score, CEA carcinoembryonic antigen, CA19-9 carbohydrate antigen 19-9

Table 3 Unadjusted and adjusted hazard ratios for resection in patients with resectable colorectal liver metastases without neoadjuvant chemotherapy versus neoadjuvant chemotherapy

\begin{tabular}{|c|c|c|c|c|c|c|c|c|c|}
\hline \multirow[t]{2}{*}{ Endpoint } & \multicolumn{3}{|c|}{ Crude } & \multicolumn{3}{|c|}{ Adjusted $^{a}$} & \multicolumn{3}{|c|}{ IPTW $^{\mathbf{b}}$} \\
\hline & $\mathrm{HR}$ & $\begin{array}{l}95 \% \\
\mathrm{Cl}\end{array}$ & $P$-value & $\mathrm{HR}$ & $\begin{array}{l}95 \% \\
\mathrm{Cl}\end{array}$ & $P$-value & $\mathrm{HR}$ & $\begin{array}{l}95 \% \\
\mathrm{Cl}\end{array}$ & $P$-value \\
\hline RFS & 1.942 & $\begin{array}{l}1.057- \\
3.568\end{array}$ & 0.032 & 1.616 & $\begin{array}{l}0.831- \\
3.144\end{array}$ & 0.157 & 1.141 & $\begin{array}{l}0.547- \\
2.380\end{array}$ & 0.724 \\
\hline
\end{tabular}

${ }^{a}$ Adjusted for variable such as those were significant in the univariate analysis ${ }^{\text {b }}$ Adjusted by IPTW

HR hazard ratio, IPTW inverse probability of treatment weighing 


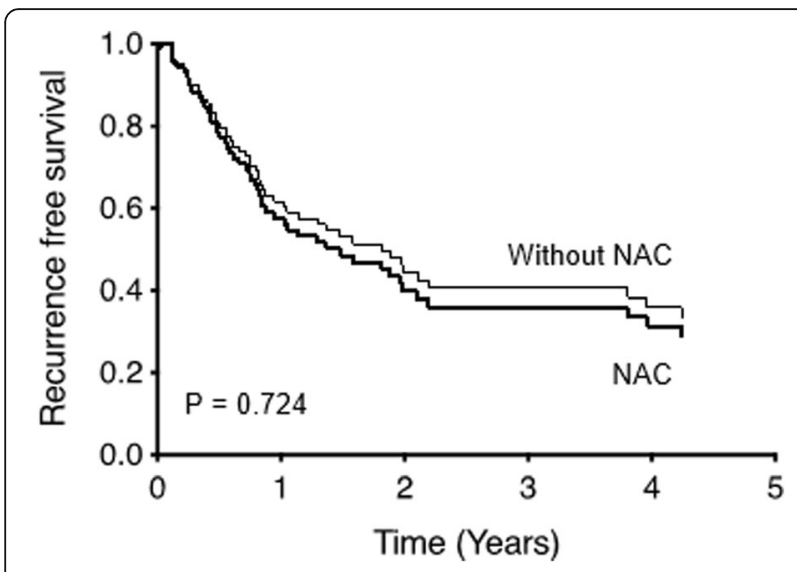

Fig. 2 Inverse probability of treatment weighting (IPTW). IPTW shows there is no significant difference in the recurrence-free survival (RFS) rate between the patients who received neoadjuvant chemotherapy (the NAC+ group) and those who did not (the NACgroup) $(P=0.724)$

matching using IPTW analysis was performed. Therefore, it is not easy to conclude whether or not NAC is efficacious for improving long-term survival in patients with CRLM. However, it is difficult to confirm our results by performing randomized controlled trials at multiple facilities due to recent increase in negative opinions about NAC for resectable CRLM [18, 19]. Beppu's nomogram score easily calculated and precisely predicted the long-term prognosis. However, it is not the only available predictor. Several reports have identified other potential biomarkers for predicting the prognosis [20]. These include circulating tumor DNA (ctDNA) for the prediction of CRC recurrence [21] and circulating tumor cells (CTCs) [22] for the prediction of CRLM recurrence after radical resection.

In conclusion, NAC does not improve recurrence-free survival for CRLM. Upfront surgery without neoadjuvant systemic chemotherapy could be considered for resectable CRLM. Beppu's nomogram score is a potential tool for predicting prognosis.

\section{Abbreviations \\ CRC: Colorectal cancer; CRLM: Colorectal liver metastasis; NAC: Neoadjuvant chemotherapy; DFS: Disease-free survival; 5FU: 5-Fluorouracil; LV: Leucovorin; CA19-9: Carbohydrate antigen 19-9; CT: Computed tomography; OS: Overall survival; RFS: Recurrence-free survival; Cl: Confidence interval; IPTW: Inverse probability of treatment weighting; ctDNA: Circulating tumor DNA; CTC: Circulating tumor cell}

\section{Acknowledgements}

None

\section{Authors' contributions}

All authors participated in the operation or management of the patient in this study. KO and TA drafted and revised the manuscript. TN is the chairperson of our department and supervised the writing of the manuscript. All authors have read and approved the final manuscript.
Funding

None

Availability of data and materials

The data that support the findings of this study are available from the corresponding author upon reasonable request.

\section{Declarations}

\section{Ethics approval and consent to participate}

The study was conducted in accordance with the ethical standards laid down in the 1964 Declaration of Helsinki. The study design was approved by our institutional review board (OJH-201509), and all patients provided informed consent for their treatment.

\section{Consent for publication}

Not applicable

\section{Competing interests}

The authors declare that they have no competing interests.

\section{Author details}

${ }^{1}$ Department of Surgery, Onomichi General Hospital, 1-10-23 Hirahara Onomichi, Hiroshima 722-8508, Japan. ${ }^{2}$ Department of Gastroenterological and Transplant Surgery, Applied Life Sciences, Institute of Biomedical and Health Sciences, Hiroshima University, 1-2-3 Kasumi, Hiroshima 734-8551, Japan. ${ }^{3}$ Department of Surgery, Hiroshima Citizens Hospital, 7-33 Motomachi, Hiroshima 730-8518, Japan.

Received: 9 November 2020 Accepted: 22 March 2021

Published online: 05 April 2021

\section{References}

1. Rudy DR, Zdon MJ. Update on colorectal cancer. Am Fam Physician. 2000; 61:1759-70 1773-4.

2. Moris D, Ronnekleiv-Kelly S, Kostakis ID, Tsilimigras DI, Beal EW, Papalampros A, et al. Operative results and oncologic outcomes of associating liver partition and portal vein ligation for staged hepatectomy (ALPPS) versus two-stage hepatectomy (TSH) in patients with unresectable colorectal liver metastases: a systematic review and meta-analysis. World J Surg. 2018;42: 806-15.

3. Fong Y, Fortner J, Sun RL, Brennan MF, Blumgart LH. Clinical score for predicting recurrence after hepatic resection for metastatic colorectal cancer: analysis of 1001 consecutive cases. Ann Surg. 1999;230(3):309-18; discussion 18-21. https://doi.org/10.1097/00000658-199909000-00004.

4. Pawlik TM, Scoggins CR, Zorzi D, Abdalla EK, Andres A, Eng C, et al. Effect of surgical margin status on survival and site of recurrence after hepatic resection for colorectal metastases. Ann Surg. 2005;241(5):715-22, discussion 22-4. https://doi.org/10.1097/01.sla.0000160703.75808.7d.

5. Mitry E, Fields AL, Bleiberg H, Labianca R, Portier G, Tu D, et al. Adjuvant chemotherapy after potentially curative resection of metastases from colorectal cancer: a pooled analysis of two randomized trials. J Clin Oncol. 2008;26(30):4906-11. https://doi.org/10.1200/JCO.2008.17.3781.

6. Nordlinger B, Sorbye H, Glimelius B, Poston GJ, Schlag PM, Rougier P, et al. Perioperative chemotherapy with FOLFOX4 and surgery versus surgery alone for resectable liver metastases from colorectal cancer (EORTC Intergroup trial 40983): a randomised controlled trial. Lancet. 2008; 371(9617):1007-16. https://doi.org/10.1016/S0140-6736(08)60455-9.

7. Van Cutsem E, Nordlinger B, Cervantes A, Group EGW. Advanced colorectal cancer: ESMO Clinical Practice Guidelines for treatment. Ann Oncol. 2010;21: v93-7. https://doi.org/10.1093/annonc/mdq222.

8. Nordlinger B, Sorbye H, Glimelius B, Poston GJ, Schlag PM, Rougier P, et al. Perioperative FOLFOX4 chemotherapy and surgery versus surgery alone for resectable liver metastases from colorectal cancer (EORTC 40983): long-term results of a randomised, controlled, phase 3 trial. Lancet Oncol. 2013;14(12): 1208-15. https://doi.org/10.1016/S1470-2045(13)70447-9.

9. Khoo E, O'Neill S, Brown E, Wigmore SJ, Harrison EM. Systematic review of systemic adjuvant, neoadjuvant and perioperative chemotherapy for resectable colorectal-liver metastases. HPB (Oxford). 2016;18(6):485-93. https://doi.org/10.1016/j.hpb.2016.03.001. 
10. Beppu T, Sakamoto Y, Hasegawa K, Honda G, Tanaka K, Kotera Y, et al. A nomogram predicting disease-free survival in patients with colorectal liver metastases treated with hepatic resection: multicenter data collection as a Project Study for Hepatic Surgery of the Japanese Society of Hepato-BiliaryPancreatic Surgery. J Hepatobiliary Pancreat Sci. 2012;19(1):72-84. https:// doi.org/10.1007/s00534-011-0460-z.

11. Higuchi A, Aoyama T, Kazama K, Murakawa M, Atsumi Y, Katayama Y, et al. Beppu's nomogram score is an independent prognostic factor for colorectal liver metastasis receiving perioperative chemotherapy and/or targeted therapy. In Vivo. 2019;33(4):1301-6. https://doi.org/10.21873/invivo.11603.

12. Halpern EF. Behind the numbers: inverse probability weighting. Radiology. 2014;271(3):625-8. https://doi.org/10.1148/radiol.14140035.

13. Mezhir JJ, Tang LH, Coit DG. Neoadjuvant therapy of locally advanced gastric cancer. J Surg Oncol. 2010;101(4):305-14. https://doi.org/10.1002/ jso.21483.

14. Hyngstrom JR, Posner MC. Neoadjuvant strategies for the treatment of locally advanced esophageal cancer. J Surg Oncol. 2010;101(4):299-304. https://doi.org/10.1002/jso.21479.

15. Van Cutsem E, Cervantes A, Adam R, Sobrero A, Van Krieken JH, Aderka D, et al. ESMO consensus guidelines for the management of patients with metastatic colorectal cancer. Ann Oncol. 2016;27(8):1386-422. https://doi. org/10.1093/annonc/mdw235.

16. Kambakamba P, Linecker M, Alvarez FA, Samaras P, Reiner CS, Raptis DA, et al. Short chemotherapy-free interval improves oncological outcome in patients undergoing two-stage hepatectomy for colorectal liver metastases. Ann Surg Oncol. 2016;23(12):3915-23. https://doi.org/10.1245/s10434-0165419-5.

17. Imai K, Benitez CC, Allard MA, Vibert E, Cunha AS, Cherqui D, et al. Impact of surgical treatment for recurrence after 2-stage hepatectomy for colorectal liver metastases, on patient outcome. Ann Surg. 2019;269(2):322-30. https:// doi.org/10.1097/SLA.0000000000002472.

18. Liu W, Zhou JG, Sun Y, Zhang L, Xing BC. The role of neoadjuvant chemotherapy for resectable colorectal liver metastases: a systematic review and meta-analysis. Oncotarget. 2016;7(24):37277-87. https://doi.org/10.1 8632/oncotarget.8671.

19. Adam R, Bhangui P, Poston G, Mirza D, Nuzzo G, Barroso E, et al. Is perioperative chemotherapy useful for solitary, metachronous, colorectal liver metastases? Ann Surg. 2010;252(5):774-87. https://doi.org/10.1097/SLA. 0b013e3181fcf3e3.

20. Liu W, Wang K, Han Y, Liang JY, Li YH, Xing BC. Nomogram predicted disease free survival for colorectal liver metastasis patients with preoperative chemotherapy followed by hepatic resection. Eur I Surg Oncol. 2019;45(11): 2070-7. https://doi.org/10.1016/j.ejso.2019.06.033.

21. Reinert T, Henriksen TV, Christensen E, Sharma S, Salari R, Sethi H, et al. Analysis of plasma cell-free DNA by ultradeep sequencing in patients with stages I to I|| colorectal cancer. JAMA Oncol. 2019;5(8):1124-33. https://doi. org/10.1001/jamaoncol.2019.0528.

22. Seeberg LT, Waage A, Brunborg C, Hugenschmidt H, Renolen A, Stav I, et al. Circulating tumor cells in patients with colorectal liver metastasis predict impaired survival. Ann Surg. 2015;261(1):164-71. https://doi.org/10.1097/SLA. 0000000000000580 .

\section{Publisher's Note}

Springer Nature remains neutral with regard to jurisdictional claims in published maps and institutional affiliations.

Ready to submit your research? Choose BMC and benefit from:

- fast, convenient online submission

- thorough peer review by experienced researchers in your field

- rapid publication on acceptance

- support for research data, including large and complex data types

- gold Open Access which fosters wider collaboration and increased citations

- maximum visibility for your research: over $100 \mathrm{M}$ website views per year

At BMC, research is always in progress.

Learn more biomedcentral.com/submissions 